\title{
Redefining Autism
}

\author{
David Rowland* \\ Canadian Association for Neuroscience, Independent Researcher registered with ORCID, Canada
}

Received Date: August 04, 2020; Accepted Date: August 12, 2020; Published Date: August 21, 2020

"Corresponding author: David Rowland, Canadian Association for Neuroscience, Independent Researcher registered with ORCID, Canada. Email: david222@ hush.com

\section{Abstract}

Autism is neither neurodevelopmental nor a disorder. It is simply an inherent neurophysiological difference in how the brain processes information. We who are autistic live in a specialized inner space that is entirely intellectual, free from emotional and social distractions. We observe the world in scholarly detail but without any emotional attachment to what we see. It may be time for the American Psychiatric Association (APA) to consider if autism should continue to be included in its Diagnostic and Statistical Manual of Mental Disorders (DSM-5).

\section{Introduction}

Autism, from the Greek word meaning self, was coined in 1911 by Swiss psychiatrist, Eugen Bleuler, who used it to describe withdrawal into one's inner world [1]. Autistic children appear to be in a world of their own isolated and alone, with senses that can easily overload. There is a recently coined word for autism in the Maori language: "takiwātanga".It means "in his/her own space" [2].

In 1943, psychiatrist Leo Kanner studied the case histories of 11 highly intelligent children who shared a common set of symptoms consistent with autism: the need for solitude, the need for sameness, to be alone in a world that never varied [3].

In 1944, medical professor Hans Asperger studied four boys whom he considered autistic because of their shutting off relations between self and the outside world [4]. Asperger described these boys as having an autistic personality that is an "extreme variant of male intelligence". He felt that their severe difficulties with social integration were compensated for by the kind of high level of thought and experience that can lead to exceptional achievements in later life.

From intimate knowledge of my own brain, I can affirm that autism is not a withdrawal. It is simply a specialized way of being in the world. We who are autistic observe the world in scholarly detail, but without any emotional attachment to what we see. We are simply living in our own intellectual space.

\section{Epidemic of False Diagnoses}

In 2020, the Centers for Disease Control (CDC) reported that 1 in 54 children is diagnosed with an autism spectrum disorder, for a prevalence rate of $1.85 \%$ of the population [5]. In 2012, a review of global prevalence of autism found 62 cases per 10,000 people, for a prevalence rate of 0.62 percent [6]. This apparent 300 percent increase in autism prevalence is in stark contrast to all other disorders listed in the Diagnostic and Statistical Manual of Mental Disorders (DSM-5), for which there has been no increase in prevalence over this same eightyear period.

A 10-year Swedish study in 2015 concluded that although the prevalence of the autism phenotype has remained stable, clinically diagnosed autism spectrum disorder has increased substantially [7]. A 2016 study reported that many children originally diagnosed with autism spectrum disorder were later found not to be autistic [8]. A comprehensive 2019 study in JAMA Psychiatry indicates that autism is being significantly over diagnosed [9]. Dr. Laurent Mottron, co-author of this most recent study, has expressed these concerns: "The autism category has considerably overextended ...most neurogenetic 
and child psychiatry disorders that have only a loose resemblance with autism can now be labeled autistic ... you could not have ADHD and autism before 2013, now you can."[10] Doctors now tend to label as autistic anyone who simply has ADHD and poor socialization.

\section{The Misleading Spectrum}

This epidemic of false diagnoses coincides with a broadening of the definition of autism. In 2013, the American Psychiatric Association (APA) merged the following four disorders under the umbrella of autism spectrum disorder (ASD): autism disorder, Asperger syndrome, childhood disintegrative disorder, and pervasive development disorder not otherwise specified (PDD-NOS). Autism now includes a spectrum of conditions of uncertain similarity. Professionals diagnose by ticking off subjective symptoms on a checklist without questioning the possible causes of said symptoms.

The APA defines autism spectrum disorder as "a neurodevelopment disorder that is characterized by difficulties with social communication and social interaction and restricted and repetitive patterns in behaviors, interests, and activities" [11]. TheDSM-5describes autism as being characterized by (1) persistent deficits in social communication and social interaction; and (2) restricted, repetitive patterns of behavior, interests, or activities. These criteria are so vague as to be meaningless. If you do not know what causes specific symptoms, then you know nothing about any presumed disorder in question.

The spectrum idea falsely implies that there can be different kinds of autism and varying degrees or levels of autism. Not so. Autism is 100 percent. Either one is autistic, or s/he is not.

\section{Absence of Pathology}

Autism can only be understood from the inside looking out. Those looking in have no frame of reference by which to understand what it is they are observing. What autistic people experience in themselves as idiosyncrasy, others misinterpret as aberration.

Autism is simply a neurophysiological anomaly. The only thing different about an autistic brain is the specialized way in which it processes information.As such, autism does not fit the medical definition of disorder, i.e., a pathological or diseased condition of mind or body. Newton, Michelangelo, Mozart, Paganini, Darwin, Jefferson, Edison, Tesla, and Einstein were autistic and can in no way be considered to have been suffering from any kind of mental pathology.

\section{Autistic Traits Have a Common Cause}

From intimate knowledge of my own autistic brain and from studying the behavior of 21 other autistic people (including three family members), I have compiled a list of 50 traits that all 22 of us have in common. These autistic characteristics appear to have a single cause: hyper focus, the perpetual and unrelenting state of intense single-minded concentration fixated on one thing at a time, to the exclusion of everything else. Hyperfocus thus appears to be the unique and defining causal state of autism that creates its observed characteristics [12, 13].

Hyperfocus keeps a person perpetually trapped in the mental/intellectual part of his mind with no ability to divide attention between two thoughts (or stimuli), thus making it impossible to feel emotions as they happen. S/he can only process emotions intellectually, a process that may take 24 hours or so. Without the ability to feel emotion, it is impossible to be spontaneous, to be emotionally available, to feel connected to others, or to be aware of how one is perceived. Anthony Hopkins spoke for every autistic person when he is reputed to have said, "My whole life I have felt like an outsider."

\section{Autistic Hyperfocus}

Hyperfocus is the unique and defining characteristic of autism that is responsible for all 50 of its observed traits listed below. Hyperfocus is the perpetual and unrelenting state of intense single-minded concentration fixated on one thought pattern at a time, to the exclusion of everything else. All 50 of these traits are caused by the inability to run two mental programs simultaneously.

Approximately one-third of the traits below can also have other causes. That is why the symptom survey approach to diagnosing fails. Without understanding causality, the categorizing of symptoms creates only confusion. 


\begin{tabular}{|c|c|}
\hline Mental Traits & $\begin{array}{ll}\text { - } & \text { Intense single-mindedness } \\
\text { - } & \text { Trapped in thoughts } \\
\text { - } & \text { Mind always busy, tendency to overthink } \\
\text { - } & \text { Passionately pursues interests, often to extremes } \\
\text { - } & \text { Amasses encyclopedic knowledge about areas of interest } \\
\text { - } & \text { Self-awareness but no social awareness } \\
\text { - } & \text { Interruptions trigger agitation, confusion, or anxiety } \\
\text { - } & \text { Cannot multitask }\end{array}$ \\
\hline Sensory Overload & $\begin{array}{ll}\text { - } & \text { Hypersensitive to loud noises and bright lights } \\
\text { - } & \text { Experiences anxiety from being mentally trapped in a sensory assault } \\
\text { - } & \text { Overwhelmed from hearing unwanted conversations } \\
\text { - } & \text { Overwhelmed by too much information } \\
\text { - } & \text { Coping with electronics and filling out forms may cause anxiety } \\
\text { - } & \text { Sensory overload makes it impossible to think or focus } \\
\text { - } & \text { Difficulty listening to radio or talking with others while driving } \\
\end{array}$ \\
\hline Emotional Traits & $\begin{array}{ll}\text { - } & \text { Unable to feel emotion } \\
\text { - } & \text { Processes emotions intellectually } \\
\text { - } & \text { Has generalized physiological responses instead of emotions } \\
\text { - } & \text { Anxiety bypasses the intellect to warn of unprocessed emotions } \\
\text { - } & \text { Incapable of experiencing fear } \\
\text { - } & \text { Can be angry without knowing so } \\
\text { - } & \text { Never (or rarely) cries or laughs } \\
\text { - } & \text { Cannot nurture self psychologically } \\
\text { - } & \text { Shrinks from emotional displays by others } \\
\text { - } & \text { Unable to defend against emotional attacks } \\
\end{array}$ \\
\hline Social Traits & $\begin{array}{ll}\text { - } & \text { Considers self to be an outsider } \\
\text { - } & \text { Lacks innate desire to socialize } \\
\text { - } & \text { Unaware of feelings, needs, and interests of others } \\
\text { - } & \text { No awareness of how perceived by others } \\
\text { - } & \text { Unaware of socially appropriate responses } \\
\text { - } & \text { Cannot pick up on subtleties, unable to take hints } \\
\text { - } & \text { Unable to read body language }\end{array}$ \\
\hline In Conversation & $\begin{array}{ll}\text { - } & \text { Speaks factually with no trace of emotion } \\
\text { - } & \text { Takes everything literally } \\
\text { - } & \text { Easier to monologue than dialogue } \\
\text { - } & \text { Oblivious to motivations of others while they are speaking } \\
\text { - } & \text { Misses sarcasm } \\
\text { - } & \text { Misses social cues and nonverbal communication } \\
\text { - } & \text { May have difficulty following topic changes } \\
\end{array}$ \\
\hline In Relationships & $\begin{array}{ll}\text { - } & \text { Understands love intellectually but cannot feel love } \\
\text { - } & \text { May understand empathy but unable to feel it } \\
\text { - } & \text { Cannot be emotionally available to others } \\
\text { - } & \text { Others cannot provide an emotional safety net }\end{array}$ \\
\hline Temperament & $\begin{array}{ll}\text { - } & \text { Drawn more strongly to certain things than to people } \\
\text { - } & \text { Innate forthrightness tends to scare others } \\
\text { - } & \text { Never bored, always engaged in some mental activity } \\
\text { - } & \text { Consistent to daily routines, agitated if routine is disrupted } \\
\text { - } & \text { Spontaneity not possible, activities must be pre-planned } \\
\text { - } & \text { Cannot lie spontaneously, can tell only premeditated lies }\end{array}$ \\
\hline
\end{tabular}

Table 1: 50 Autistic Traits Caused by Hyperfocus. 


\section{Neurophysiology of the Autistic Brain}

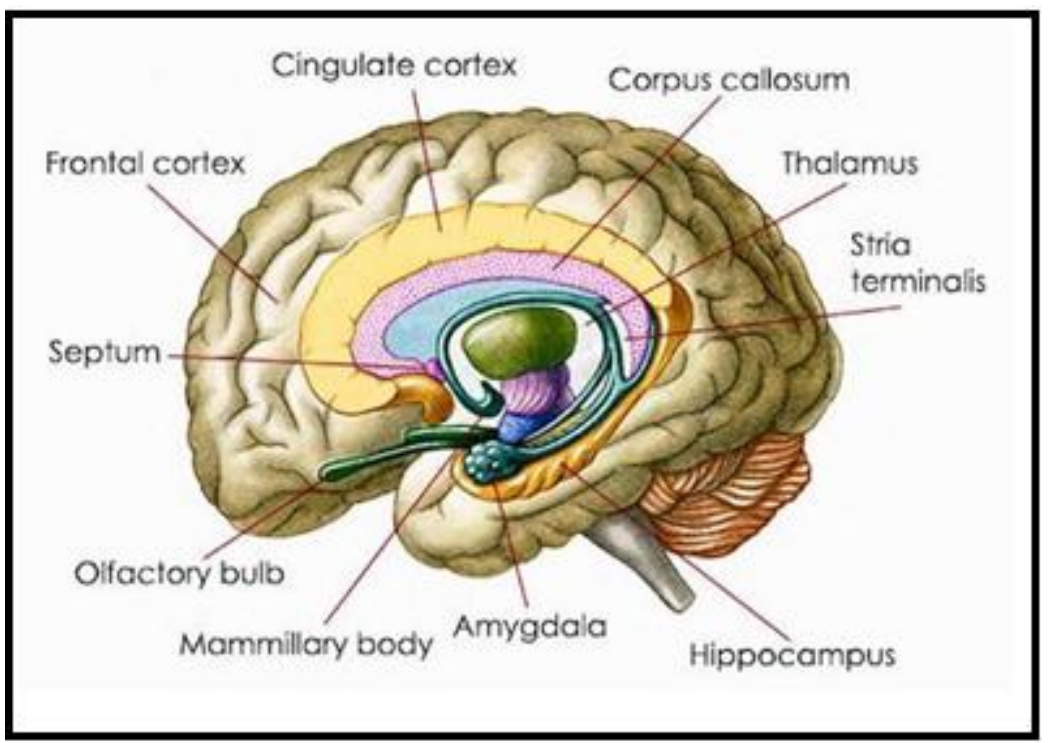

Figure 1: Image Credit: nutritionreview.org

The neurological structure of the autistic brain is the same as for any other brain. What is different about the autistic brain is how it functions with respect to its neurophysiology.

\begin{tabular}{|c|l|l|}
\hline $\begin{array}{c}\text { Cingulate } \\
\text { Cortex/Gyrus }\end{array}$ & Dysfunctional & $\begin{array}{l}\text { The cingulate gyrus (CG) is that part of the brain which focuses attention. In autism, the CG } \\
\text { appears to keep the person's attention trapped in the left frontal lobe, creating a perpetual state of } \\
\text { hyperfocus. }\end{array}$ \\
\hline $\begin{array}{c}\text { Left Frontal } \\
\text { Cortex/Lobe }\end{array}$ & Dysregulated & $\begin{array}{l}\text { In the autistic left frontal lobe, alpha frequencies (8-12 Hz) predominate over beta (12.5-30 Hz), } \\
\text { which is the exact opposite of the neurotypical brain. Higher alpha frequencies in the left brain } \\
\text { appear to be compensating for the inability to access creativity and intuition from the right brain. }\end{array}$ \\
\hline $\begin{array}{c}\text { Right Frontal } \\
\text { Cortex/Lobe }\end{array}$ & Inaccessible & $\begin{array}{l}\text { There is normal brainwave activity in the right frontal lobe, with alpha frequencies predominating } \\
\text { over beta. However, neural networks are suspected of being underdeveloped. The autistic person } \\
\text { is completely unaware of anything that happens in his/her right frontal lobe, the place where } \\
\text { emotions and social connectivity are experienced. }\end{array}$ \\
\hline Amygdala & Inactive & $\begin{array}{l}\text { The amygdala plays a central role in the expressing of emotions, especially fear. A dysfunctional } \\
\text { CG prevents the autistic person from feeling any emotion, with the result that the amygdala is } \\
\text { virtually non-functioning. An autistic person typically never experiences fear. }\end{array}$ \\
\hline
\end{tabular}

Table 2: Autistic Neurophysiology.

In a neurotypical brain, the cingulate gyrus (CG) acts like an automatic transmission that seamlessly switches attention back and forth between frontal lobes, as required. In autism, however, a dysfunctional CG keeps the person trapped in his/her left frontal lobe (logical/analytical) - with no ability to access the right frontal lobe (emotional/creative), which plays a central role in spontaneity, social behavior, and nonverbal abilities. Some neurotypical people are left-brain dominant whereas others are right brain dominant. Autistic people, however, are left brain exclusive. They speak factually, with no trace of emotion, and with a deadpan facial expression.
Hyperfocus also causes various kinds of sensory overload. A sudden loud or high-pitched noise switches hyperfocus to the noise, which the autistic person then experiences with many times the intensity than does a neurotypical person. Seeing too many words on a page can cause cognitive impairment whereby the autistic person's mind goes disturbingly blank. Too many products on shelves and overhearing unwanted conversations in stores can trigger anxiety. Lighting displays can trigger intense anxiety. For some, hyperfocus exaggerates the sense of touch, making close fitting clothing irritating and hugs unbearable. 


\section{The Futility of Therapy}

It is not possible to fix that which is not broken. Autism is an inherent neurophysiological way of functioning that cannot be altered.

Therapies for autism are aimed at socializing the child. It cannot be done. It is no more possible to socialize an autistic person than it would be to intellectualize a neurotypical person. The autistic brain inherently works in a precise way that cannot be changed. No one can be talked out of inherent hyperfocus.

Applied Behavior Analysis (ABA) is the most common therapy that is attempted for autistic children. It is an intensive one-on-one program that aims to improve social skills by increasing desirable behaviors and decreasing problem behaviors. There is a vocal community of adults with autism (many of whom had ABA as children) who say that ABA is harmful because it is based on the cruel premise of trying to make people with autism "normal" [14].

\section{Differential Diagnosis}

Differential diagnosis is distinguishing a specific condition from others that may have similar clinical features. The neurophysiological differences between autism and conditions for which it is mistaken can be profound.

Both attention deficit hyperactivity disorder (ADHD) and obsessive-compulsive disorder (OCD) share a common trait, fickle focus, which is defined as intervals of intense mental fixation interspersed with episodes of distraction or impulsiveness. Fickle focus can look like hyperfocus that comes and goes; however, true hyperfocus is perpetual and unrelenting. Autistic people never get any relief from hyperfocus.

Because of the confusion between fickle focus and hyperfocus, many people with ADHD or OCD are misdiagnosed as being on the autism spectrum. Also, some who are truly autistic are given false multiple diagnoses that include either ADHD or OCD or both.

Autism appears to be entirely neurophysiological in origin. ADHD and OCD appear to be caused or aggravated by a biochemical imbalance of neurotransmitters. Low dopamine is suspected in ADHD and low serotonin suspected in OCD.

\begin{tabular}{|l|l|l|l|}
\hline & Autism & ADHD & OCD \\
\hline Hyperfocus & Hyperfocus & Fickle \\
\hline Cingulate Gyrus & Dysfunctional & Fickle focus ${ }^{2}$ & Fickle $^{2}$ \\
\hline Amygdala & Inactive & Functional & Functional \\
\hline Left Frontal Lobe & High alpha activity. & Active & Active \\
\hline Neurochemical Imbalance & n/a & Ligh beta activity. & High beta activity. \\
\hline Concentration & Intense & Intense & Low serotonin suspected. \\
\hline Distraction & Never distracted. & Sometimes distracted. & Intense \\
\hline Multitasking & Unable to multitask. & May be able to multitask. & Unable to multitask. \\
\hline Emotional Aspects & $\begin{array}{l}\text { Incapable of feeling emotion. } \\
\text { Processes emotions } \\
\text { intellectually. }\end{array}$ & $\begin{array}{l}\text { Can trigger intense } \\
\text { emotions. }\end{array}$ & $\begin{array}{l}\text { Compulsive behaviors may } \\
\text { be attempts to alleviate } \\
\text { emotional distress. }\end{array}$ \\
\hline Social Aspects & $\begin{array}{l}\text { Unable to understand and } \\
\text { respond to emotional needs of } \\
\text { others. }\end{array}$ & Poor social skills. & Social anxiety. \\
\hline
\end{tabular}

${ }^{1}$ Hyperfocus is perpetual and unrelenting attention fixated on one thought or stimulus at a time, to the exclusion of everything else.

${ }^{2}$ Fickle focus consists of intervals of intensely paying attention interspersed with episodes of distraction or impulsiveness.

Table 3: Comparative Neurophysiology and Neuropsychology.

\section{Autistic Fearlessness}

Autistic people do not have an involuntary fear response. In every dangerous or life-threatening situation, the autistic person is fully focused on the event itself and incapable of feeling fear or even nervousness in that moment. S/he feels a mildly heightened sense of awareness while coldly calculating risks and mitigating factors that quickly form an immediate plan of action. In my entire life, including 17 years of experience in martial arts, I have never once felt fear of any kind.

Sometimes autistic people may intellectualize about fear, for example saying that after thinking about such-and-such decided it could be a scary thing. However, they are incapable of feeling fear. If you encounter someone who has never felt 
fear, this person is most probably locked into autistic hyperfocus.

\section{A Litmus Test for Autism}

Hyperfocus is the unique and defining causal state of autism that creates its observed characteristics. Hyperfocus prevents someone from dividing attention between two thought patterns or two stimuli at the same time. An autistic person talking to you is incapable of feeling any emotion in that moment. The surest way to find out if someone is autistic is to ask these five questions, to which you will receive the following responses $[10,11]$.

\begin{tabular}{|c|c|c|}
\hline 1. & How often do you cry? & "never" or "rarely" \\
\hline 2. & How often do you laugh? & "never" or "rarely" \\
\hline 3. & What are you afraid of? & "nothing" or an intellectual answer \\
\hline 4. & What are you feeling now? & "nothing" or an intellectual answer \\
\hline 5. & Do you ever get bored? & "never" \\
\hline
\end{tabular}

Example of an intellectual answer:

“No, I'm not angry. That wouldn't be logical."

Anyone who answers all five questions as above is autistic. Anyone who answers four or fewer as above is not autistic.

Note: If the person answers the third question with a phobia (e.g., of heights), then re-ask the question this way, "Aside from this phobia, do you normally experience fear of any kind?"

\section{Intensity of Autism}

The only variable within autism is the intensity with which hyperfocus is experienced. Low functioning autistic people are so intensely locked into hyperfocus as to be noncommunicative. There is a middle range of intensity wherein a highly intelligent child has an atypical speech pattern, slow mental processing time, and echolalia (automatically repeating vocalizations made by others). High functioning autistic people (Asperger syndrome) are the ones least intensely locked into hyperfocus. The degree to which one is challenged by sensory overload issues corresponds to the intensity of hyperfocus.

In my family, one young lad was born with non-communicative autism. His younger brother was born with Asperger syndrome. Clearly, both extremes are the same genetic hyperfocus.

Naoki Higashida is an autistic person who is entirely aware but unable to communicate using speech. At age 13, he typed out a book (one keystroke at a time) that explained the reasons for his erratic running, clapping, and jumping that drew stares from others $[\mathbf{1 5}, \mathbf{1 6}]$.

Einstein started life with intense hyperfocus. He did not speak until age four and had echolalia until age seven. There is no known therapy that can reduce the intensity of inherent hyperfocus. Somehow Einstein managed to do this on his own.

\section{Our Inner World}

We who are autistic thoroughly enjoy our inner intellectual world. It is an exciting place in which we are continually learning and discovering, finding answers to questions that most people do not think to ask. Our innate skill at logic enables us to separate out what is important from what is not, thereby turning complexity into simplicity. We are self-motivated achievers who delight in what we accomplish.

Autistic people who cannot communicate enjoy their inner intellectual world just as much as those of us who can. Whether they spend their time fixated on televised cartoon shows or silently exploring the universe with their iPads, they are delighting in that experience.

The autistic brain cannot be socialized. We voluntarily associate with others when necessary in pursuing a passion, such as playing a musical instrument or participating in track and field events. We prefer to be the initiators of what little social contact we require. It is distressing when others try to force us to conform to social norms.

\section{Conclusion and Recommendations}

The psychology professions now require a causal based definition and description of autism, for which I recommend the following:

- Definition: Autism is perpetual and unrelenting hyperfocus, the state of intense single-minded concentration fixated on one thing at a time to the exclusion of everything else, including one's own feelings. The probable cause of hyperfocusis a dysfunctional cingulate gyrus (CG), that part of the brain which focuses attention [15].

- Description: Autism is an inherent neurophysiological difference in how the brain processes information. Autistic people live in a specialized inner space that is entirely intellectual, free from emotional and social distractions. They tend to observe the world in scholarly detailwithout feeling any emotional attachment to what theysee. 
The DSM-5 assumes that autism is a mental disorder. Not so. Autism is simply a specialized intellectual way of functioning. There is no pathology involved. There is no therapy that change an autistic brain.

Therefore, my second recommendation is that the Autism Spectrum Disorder (ASD) category be removed from the DSM5 and replaced with a Neurodevelopmental Disorders category that correctly identifies conditions that are to be subsumed under this new heading.

\section{References}

1. Blatt G. “Autism”, Encyclopedia Britannica.

2. Opai K."A time and space for takiwātanga". Altogether Autism Takiwātanga.

3. Kanner L (1943) Autistic disturbances of affective contact, Nervous Child 2: 217-250.

4. Asperger H (1991) Autistic psychopathy' in childhood. Autism and Asperger Syndrome, edited by UtaFrith.Cambridge: Cambridge University Press, pp 3792.

5. "Autism Statistics and Facts". Autism Speaks.

6. Elsabbagh M, Divan G, Yun-JooKoh, Kim YS, et al. (2012) Global prevalence of autism and other pervasive developmental disorders. Autism Res 5: 160-179.
7. Lundström S, Reichenberg A, Anckarsäter H, Lichtenstein P, Gillberg, C (2015) Autism phenotype versus registered diagnosis in Swedish children: prevalence trends over 10 years in general population samples. British Medical Journal Apr 28.

8. Blumberg SJ, Zablotsky B, Avila RM, Colpe LJ, Pringle BA, et al. (2016) Diagnosis Lost: Differences between children who had and who currently have an autism spectrum diagnosis. Autism 20: 783-795.

9. Rodgaard E, Jensen K, Vergnes J, Soulières I, Mottron L (2019) Temporal changes in effect sizes of studies comparing individuals with and without autism: a metaanalysis. JAMA Psychiatry 76: 1124-1132.

10. “Are We Overdiagnosing Autism". Healthline.com

11. "Autism Spectrum Disorder". American Psychological Association.

12. Rowland D (2020) Differential diagnosis of autism: a causal analysis. J NeurolNeurophysiol 11:489.

13. Rowland, D.Autism as an intellectual lens. Journal of Neurology, Psychiatry and Brain Research, Volume 2020, Issue 01.

14. Rowland D (2020) A need to redefine autism. Journal of Neurology \& Neurophysiology 11: 001-004.

15. Higashida N (2016) The Reason I Jump: The Inner Voice of a Thirteen-year-old Boy with Autism, 2016.

16. Higashida N (2019) Fall Down 7 Times Get Up 8:A Young Man's Voice from the Silence of Autism, 2019.

Citation: Rowland D (2020) Autism as an Intellectual Lens. Jr Neuro Psycho and Brain Res: JNPBR-147. 